\title{
Lope de Vega: de la Sumisión a la Rebeldía*
}

\author{
NOTAS SOBRE EL "ARTE NUEVO DE HACER COMEDIAS"
}

\section{Por: Antonio Connejo Polar}

Tiempo hace que en San Marcos no se oía una voz agustina. $Y$ es sensible que el largo silencio se rompa no con la palabra de un maesiro consagrado y sapiente, que los hay en San Agustín, sino con la audacia de un profesor que se inicia en la cálida angustia del aprender-enseñar cotidiano e interminable.

Abrumado de responsabilidad, incómodo de tanto honor, no puedo menos que exculpar mis deficiencias en la generosidad del doctor Luis Alberto Sánchez, Rector de San Marcos y de la historia literaria americana $y$ del doctor Guillermo Ugarte Chamorro, gran responsable del resurçimiento del qeatro nacional y bondadoso embajadôl dela Universidad de Árequipa en estos claustros que son - sin duda-germen, imagen y destino de la cultura del Perú.

Mi agradecimiento, también, al doclor Armando Zubizarreta, maestro en Unamuno $y$ en el "nuevo arte" de calar con hondura y saber, con sensibilidad y exactitud, en la preciosísima urdimbre de los textos literarios. Y, en general, a la Facultad de Letras; de manera especial a su dignísimo Decano, doctor Jorge Puccinelli, por su gentil deferencia para conmigo.

Que esta conferencia sea augurio de vinculaciones más fecundas entre las Universidades de San Marcos y San Agustín.

* Texto de la conferencia leída por el autor en la Facultad de Letras de San Marcos el 22 de Noviembre de 1962, como parte del ciclo en homenaje a Lope de Vega.- Es una síntesis del ensayo que, con el mismo título ha editado el Departamento de Publicaciones del Teatro Universitario de San Marcos. 
El destino de los clásicos, se ha dicho, es el 'de no ser leídos. Tristísima suerte a la que habría que añadir la del emparedamiento de sus vidas, obras y méritos tras de murallas de adjetivos insulsos e impermeables. Lope de Vega - clásico- pervive también sofocado entre derrumbes adjetivales: Fénix de icz Ingenios, Padre del Teatro Español, Monstruo de Naturaleza, elc. etc. Y los adjetivos que un día fueron luz prendida por el saber, hoy sirven de cortina de humo para la ignorancia. Por esto, para no caer en el fácil juego de las sólitas reileraciones, hemos preferido peregrinar hasta las fuentes; esto es, adentrarnos en la obra de Lope, tal como ella se descubre ante nuestra mirada, para así tributar homenaje a quien, con genialidad poderosa, pudo cambiar el rumbo de una larga tradición literaria. Cumplimos, al mismo tiempo, con el imperativo del recuerdo, ahora que se cuentan cuatro siglos del nacimiento de Lope de Vega.

Desde nuestra perspectiva cuatricentenaria, la producción de Lope aparece, con creciente y universal evidencia, como invalorable documento del instanle en que el teatro español rompe a hablar en lengua propia, al margen de los cánones clásicos del drama. Queremos cuestionar ahora cuál fue el sentido de la renovación lopeveguesca y en qué postulados basó su empeño revolucionario. En orden a tal fin nos proponemos analizar el pensamiento de Lope acerca del teatro, intentando descubrir qué elementos clásicos pudol asimilàrey qué factores nuevos pudo crear. Poseemos, felizmente un derrotero de singular importancia: el "Arte nuevo de hacer comedias" que Lope escribiera cuando contaba 47 años de vida -existencia intensa, desorbitada, vitalísima- y 483 comedias, según propio decir.

El "Arte nuevo..." es una extraña especie de manifiesto literario. En él, con restricciones y vaguedades, se expone la estructura ideológica de la renovadora creación lopesca. Y, por tanto, nada más esclarecedor que indagar en esta obra a efecto de responder las inquerencias ya planteadas.

Lo que inmediatamente atrae nuestra atención en esta obra, es lo que podríamos llamar su "tono vergonzante". En efecto, cuando Lope expone sus nuevas ideas adopta el aire del pecador que confiesa un pecado:

"Mas ninguno de todos llamar puedo más bárbaro que yo, pues contra el arte me atrevo a dar preceptos, y me dejo llevar de la vulgar corriente..." (Vs. 362-365 
No es el momento de tratar de las motivaciones de este gesto. Es dable, empero, insinuar que el mismo es el resultado del conflicto que afligía a Lope: sus enemigos (Gónçora de manera especial) lo atacaban con rudeza por considerarlo inculto; Lope, por su parte, sabía que sus conocimientos humanísticos eran confusos y superficiales, y no quería exponerse a la demoledora crítica de los académicos. Prefería, por tanto, alegar de antemano la conciencia de su pecado y no ofrecer resistencia a quienes - por hondura de saber, que no por vivacidad de genio- podían más que él. Por lo demás, para desazón de Lope, se insistía aún en la idea del poeta como hombre de suma sapiencia. Sánchez de Lima, en su "Arte Poética en Romance Castellano" de 1580, decía: "puss es claro que le merece (el nombre de poeta) sino el qua ha Ro ( $m$ ) pido su lanca, y muchas lanças en el campo, o campos de los buenos ingenios, que son las academias y universidades" Juan de la Cueva, apenas tres años antes de que Lope escribiera su "Arie nuevo..." decía en su "Exemplar Poético":

"Este renombre (de poeta) se le deve aquellos que con-erudición, doctrina y ciencia le dan ornato que los hacen bellos".

Sin embargo, si calamos más hondo en la obra de Lope, encontraremos que la "postura de confesión" es una mera apariencia. Nuestro autor, cuñúa sólo a' veces, deja desembozada su intención y se presenfal ac dar lbatallar Podriamos citar su "cierren los docios esta vez la boca", a manera de ejemplo del tono lopeveguesco cuando olvida las precauciones que él mismo se había impuesto.

En cualquier caso, y para entrar ya en materia, conviene saber que Lope de Vega expone, en síntesis, la siguiente teoría preliminar: Confiesa, en primer término, que sus comedias han sido escritas al margen del arte; esto es, contraviniendo los preceptos clásicos. Afirma en seguida que tal ha hecho no porque ignorase las normas tradicionales, que las aprendió desde su niñez, sino porque el gusto del espectador español no se complace con los dramas clásicos. Ante las exigencias de este público bárbaro y rudo- así lo llama Lópe- se decide a producir en concordancia con él:

"Que quien con arte ahora las escribe muere sin fama y galardón..." (Vs. 29-30) 
Por esto, en consideración al gusto mayoritario que rechaza las piezas tradicionales, Lope, más socarrón que afligido, nos dice:

"Y cuando he de escribir una comedia encierro los preceptos con seis llaves; saco a Terencio y Plauto de mi estudio, para que no me den voces $(. .$. $y$ escribo por el arte que inventaron los que el vulgar aplauso pretendieron porque, como las paga el vulgo, es justo hablarle en necio para darle gusto". (Vs. 40-48)

Este artificio de presentar con ademán vergonzante lo que en realidad era su gloria, le ha valido a Lope decenas de malas interpretaciones. Recordemos, escuetamente, que don Marcelino Menéndez y Pelayo calificaba el "Arte nuevo..." de "lamentable palonodia" en la que Lope renlega indignamente de su propio genio. Esto no es así. Lope de Vega carece en esta obra de energía, de explicitez, de rotundidad pero carga en la misma una buena dósis de sentido interlineado, de suave y no abierta persuación. de -en fin-acallados gestos de rebeldía. Y, en el fondo, para quien quiera ver, subyace toda una nueva concepción acerca del ser y el quehacer dramáticos.

Ahora bien: sino se acatan los preceptos de la retórica clási$c a$, ¿qué nuevas directivas debe tener el arte de escribir comedias? Por lo pronto, $\mathrm{y}$ es necesario saberlo de inmediato, Lope de Vega no desecha tódo el caudal tradicional. Acepta y asimila ciertos aspectos de la preceptiva clásica, a la sombra de Aristóteles y Cicerón.

Lope afirma, en efecto, que el fin de la "comedia verdadera" (que es el mismo, añade, de "todo género de poema o poesía") consiste en "imitar las acciones de los hombres/ y pintar de aquel siglo las costumbres". (Vs. 57 y ss.). Y Aristóteles, en su Poética, decía: "La epopeya, y aun esotra obra poética que es la tragedia, la comedia lo mismo que la poesía ditirámbica y las más de las obras para flauta y cítara, da la casualidad de que todas ellas son -todas y todo en cada una- reproducciones por imitación".

Lope, más adelante, señala que entre comedia y tragedia se encuentra la siguiente diferencia: la comedia trata de "acciones humildes y plebeyas" y la tragedia, de "acciones reales y altas". (Vs. 57-61). Y Aristóteles afirmaba: "Tal es precisamente la diferencia que separa a la tragedia de la comedia, puesto que ésta 
se propons reproducir for imitación a hombres peores que los normales, y aquélla $a$ mejores. La comedia -añade más adelante el filósofo- es reproducción imitativa de hombres viles o malos, y no de los que lo sean con cualquier especie cie maldad, sino en la maldad iea, que es, dentro de la maldad, la parte correspondierite al ridículo", mientras que "la tragedia es reproducción imitativa de acciones esforzadas, perfectas, grandiosas, en deleitable lenguaie, cada peculiar deleite en su correspondiente parte; :mitación de varones er acción, no simple recilado; e imitación que determine entre conmiseración y terror el término medio en que los afectos adquieran estado de pureza".

Si ahora comparamos lo que Lope afirma con lo expuesto en ia Poética de Aristóteles, leridremos que convenir que ésta se proyecta con fuerza sobre el "Arte nuevo...", el cual prosigue la línea arisiotélica, aunque con notorio esquematismo y hasta inseguridad. Por lo demás, es natural que Lope de Vega, que fue más un cultista que un humanista, según piensa Vossler, conociera a Arıstóteles sólo en sus lineamientos generales. De aquí que el "Arte nilevo...", para utilizar un símil de García Bacca, aparezca como una extraña criba que deja pasar lo más genéricc, pero detiene lo matizado y sutil. En sus mallas queda, por ejemplo, todo lo referente al lengnaje, al ridículo, a la catarsis, etc. etc.

Pero no sólo Aristóteles improntaba el pensar lopeveguesco. Cicerón tieneptambién vigencia sobre él. Así, cuando lope nos dice que la comedia es "espejo de las costumbres/ Y una viva imagen de la verdad" (Vs. 123 y ss.) se está refiriendo claramente al pensamiento ciceroniano. Por lo demás, siete años antes de que Lope escribiera su "Arte nuevo...", Luis Alfonso Carballo, en su poética "El cisne de Apolo", había escrito: "La comedia Es una imitación de la vida, espejo de costumbres, ymage $(n)$ de verdad, como dize el famoso orador (alude a Cicerón) en estas palabras: comedia est immitatio viiae, speculum consuetudinis \& imago veritatis". De lo que se desprende, por éste y otros testimonios, que las ideas ciceronianos eran una especie de saber común, al igual que las aristotélicas, y que Lope, por tanto, no hizo más que respirar el aire cultural que entonces corría por España.

Debemos remarcar, pues es de importancia, que la retórica clásica que Lope asimiló genéricamente, no siempre fue cabalmente entendida por nuestro autor. A guisa de ejemplo observaremos que Lope cree que la tragedia debe versar sobre acontecimientos históricos y la comedia sobre puras ficciones, lo cual es una mala 
interpretación de un texto aristotélico; que la tragedia se compone de "plática, verso dulce, armonía o sea la música", lo cual -igualmente- supone una grave confusión. Por lo demás, y para ser justos, es menester anotar que tales deficiencias se encuentran no sólo en Lope. Los tratados de Sánchez de Lima ("Arte Poética en Romance Castellano", 1580), de García Rengifo ("Arte Poética Española", 1592), del ya citado Carballo, de Juan de la Cueva, también ya conocido, y de Carrillo y Sotomayor ("Libro de la Erudición Poética", 1611) —esto es, los textos clásicos de la prereptiva española de la Edad de Oro- están afectados por similares errores y confusiones. Apenas se salva la "Philosophia Antigua Poética" de Alfonso López Pinciano (1596), obra cumbre de la erudición y el humanismo peninsulares.

Queremos demostrar, entonces, que Lope de Vega no conocía el legado clásico como humanista meditativo y sesudo, lo que hoy llamaríamos un especialista académico, sino gracias a la cultura común de la época. Por esto es fácil encontrar en su "Arte nuevo..." un conjunto de tópicos manifiestos. Algunos, los menos, puramente formales: tópico del sobrepujamiento y de la falsa modestia, según la terminología de Curtius. Otros, la mayoría, ideológicos. Lope, por ejemplo, afirma, aunque tácitamente, que la literatura debe enseñar y producir deleite. Reitera, entonces, una vieja teoría horaciana de secular vigencia en romanía y, especialmente, en España. (La intención docente ha sido el gran pecado y la gran virtud de las letras hispánicas, desde el Cid hasta Blas de Otero). Y ésta no es una simple manera de decir. En efecto, el tópico en mención se vislumbra ya en el Arcipreste de Hita y en Berceo; se manifiesta clara y teóricamente en Santillana y reaparece, como floración abundantísima, en los tratadistas del Siglo de Oro, contemporáneos de Lope.

Comenzemos por Iñigo López, Marqués de Santillana: "E ¿qué cosa es la poesía (que en nuestro vulgar gaya sçiençia llamamos ) si non un fingimiento de cosas útiles (fin docente), cubiertas e veladas con muy fermosa (placer, deleite) cobertura..."

Y Sánchez de Lima, primer retórico renaciente: "Tratando conceptos muy subidos (la poesía) mezcla(ndo) el agradable y dulce estilo, con lo provechoso y muy sentido".

Y Rengifo, el auténtico, no el de Vicens: "Los poetas han de pretender con la Poesía aprouechar, y, deleytar. Aprouecharan con la materia, si fuera de suyo buena, y deleytaran con la suavidad del metro". 
Y Carrillo: "De dos cosas trata el poeta, enderezadas a un fyn, enseñar, como arriba dixe, deleytando".

Y, por último, el Pinciano: "Las cuales (música y poesía) fueron inuentadas para dar deleyte y doctrinar juntamente".

Ahorc tien: la actitud tradicionalista de Lope no sólo atañe a estos aspectos generales. Tiene también su manifestación en algunos puntos concretos de su idea del drama. En este sentido, nuestro autor acepla totalmente una de las tres unidades prescritas por la retórica clásica. Acepta, concretamente, la unidad de acción y proclama la urgencia de que toda pieza teatral presente una estructura unitaria, de suerte, que si se le "quita un miembro" se "derriba todo" (Vs 181-187). El juicio anterior es notoriamente aristotélico: "la acción debe ser una e íntegra -leemos en la Poética- y los actos parciales deben estar unidos de modo tal que cualquiera de ellos que se quite o se mude de lugar, se cuertee y descomponga el todo".

Pero el genio de Lope no podía aferrarse en todo a esta isla de tranquilidad- la retórica dlásica- cuya goografía jamás deparaba sorpresas, normada como estaba por leyes fijas, conocidas y reconocidas. Por esto, después de 130 versos que están a punto de desilucionarnos, Lope de Vega alza vuelo e inicia la exposición de su ideario personal. Y, a manera de exordio de su requisitoria contra la vieja concepción, nos advierte que lo que viene luego no es màs gueda expresión de su propio parecer: un parecer, advierte, que brota de la mera experiencia. A nuestro modo de ver éste es uno de los goznes centrales del "Arte nuevo de hacer comedias". Aquí, en efecto, Lope respalda su nueva visión del teatro en una categoría experiencial que, tratándose de la suya, es ciertamente meritísima y avasalladora. El triunfo del teatro lopesco, apoteósis jamás contemplada por pueblo alguno, aparece como aval suficiente para cuantas innovaciones desee Lope proponer. Y nos es dable distinguir ya cómo nuestro autor va desarrollando, con finísima estrategia, la sinfonía de una nota que habrá de pulsar constantemente; esto es, el favor mayoritario de un pueblo enfervorizado - halago y encuentro- con el genio de su más sentido porta-afectos.

Por otra parte, Lope de Vega no es un iconoclasta profesional. Sabe que su arquitectura no se va a levantar sobre el desierto e intuye que por cimiento tendrá una tradición exhaus'ta pero valiosa. Luchondo entonces entre los polos del sumiso temor reverencial y de la rebeldía, de la tradición y la originalidad, Lope 
adopla teóricamente un justo medio. Su "Arte nuevo..." confórmase por ende como intento de armonizar lo que mandan los; cánones y lo que al público le place. Así se va perfilcando el rostro del teatro tal como "querría" verlo Lope, en su empeño por "dorar el error del vulgo" y vitalizar con cordialidad popular el anémico rostro del teatro clásico. La sumisión ha obrado su sortilegio: 130 versos que ya hemos reseñado. $Y$ acaece, entonces, la hora de la rebeldía; su mundo mágico y naciente, sus novedades inaugurales, sus categorías inéditas, comienzan a vislumbrarse; y sobre las aguas que se retiran de la deshumanizada tierra del teairo antiguo, aletea el espíritu de Lope.

Para comenzar, Lope, el desbocado, de quien Góngora había dicho "potro es gallardo pero va sin freno" destroza el principio de la independencia de las especies dramáticas. Hasta entonces se pensaba que la tragedia y la comedia eran mundos independientes y teníase por sumo crimen mezclar la severidad trágica con la liviandad cómica. Pero Lope, que sabía por los autos sacramentales del donaire del sucio pástorcillo ante la majestad de Jesús Dios, no podía husmear malsonancias en la fusión de lo cómico con lo trágico. Y consciente de su verdad, apoyado en el popularismo religioso de los autos sacramentales $\mathrm{y}$, tal vez, en el recuerdo de Calixto y Melibea, proclama la necesidad de romper las barreras entre las especies dramáticas. La nueva ley es mezclar lo trágico y lo cómico.chacer una partegraves otra ridícula; y -por si alguien se "escgndalizase-il Lope se remite a la naturaleza:

"Buen ejemplo nos da naturaleza

que por tal variedad tiene belleza". (Vs. 179-80)

Lope de Vega encuentra seguridad y aplomo. Ha dicho, burlón, ante la gravedad de su desacato: "perdonen los preceptos". Ahora, en vísperas de una nueva incursión allende lo clásico, comenta regocijado que Aristóteles ha perdido su vigencia:

“...ya le perdimos el respeto

cuando mezclamos la sentencia trágica

a la humildad de la bajeza cómica". (Vs. 188-92)

Lope decide, dando un nuevo paso, que la obra dramática no tiene por qué limitarse a presentar acontecimientos que sucedan en lapso no mayor de un día, conforme lo dispuesto en la 
Poética: "porque la tragedia inlenta lo más posible - dice el Esiagirita -confinarse dentro de un período solar". Y, en cambio, nuestro autor considera que con frecuencia es menester exceder dicho lapso, aunque (recuérdese que está tratando de encontrar un justo medio) no puede menos que recomendar que la acción transcurra en el menor tiempo posible. Se completa, asi, la violación del segundo dogma sagrado: el de la unidad de tiempo. Por lo demás, si el "Arte nuevo..." faculta al comediógrafo para que pueda burlar el clásico límite temporio, es porque la exexperiencia lopesca sabe que la "cólera" de las audiencias españolas no se aplaca sino cuando se les presenta en escena del Génesis al Juicio Final....

Finalmente, Lope de Vega se estrella contra otro de los pilares del teatro clásico, pero esta vez su rebeldía va más lejos: rechaza un principio general de índole socio-estética y su particular manifestación literaria Considerábase por entonces, e incluso desde muchos siglos, que el aplauso mayoritario, el favor del gran público, era, por lo menos, un síntoma del escaso valor de la obra así premiada. Un sentido típicamente aristocrático, que ya es visible en el "Arte de Trovar" del Marqués de Villena, hacía suponer que el nivel literario de una obra estaba por encima del gusto popular y que, por consiguiente, cuando sucedía que una obra deleitaba a las mayorías, era porque la misma se encontraba a tan baja altura qué hasta el gusto eplebeyo podía recrearse en ella. Se pensaba, pues, que las delicias de la literatura sólo podían ser gozadas por espíritus privilegiados y que el deber de todo buen escritor era el de defender su producción, mediante cerramientos y obscuridades, de los intrusos que quisieran gozarla. A guisa de muestra citaremos un texto de Carrillo y Sotomayor: "Con el tiempo andan oluidadas (las virtudes de la poesía), y lo anduuieron tanto, que se atreuieron a profanar de sus mas sagrados templos sus mas preciosas joyas. Presume el vulgo de entendellas, el mismo pretende juzgallas. Contra esto endereço mis razones..." De siglos anteriores, y aunque con sentido ligeramente distinto, son "las cortezas", "las razones encubiertas" y la "fermosa cobertura" de Berceo, el Arcipreste y Santillana, respectivamente.

Pues bien: Lope cree precisamente lo contrario. Hemos visto ya cómo basa toda su actitud en el gusto de las audiencias populares y cómo burla el principio de la unidad de tiempo porque tal no complace al espectador. Podríamos citar decenas de juicios 
fundados, todos ellos, en su aceptación popular: la preeminencia de los temas de honor, el extremo cuidado en los fines de acto, el principio de la tensión dramática, el uso del equívoco y la anfibología, e, incluso, la verosimilitud, son normas, consejos y principios que Lope apoya en la voluntad del nuevo rey: el gran público. A él se refiere nuestro autor cuando dice: "debo obedecer a quien mandarme puede". Y luego, ya en el plano de los juicios generales, anota:

"Yo hallo que si allí (en el teatro) se ha de dar gusto, con lo que se consigue es lo más justo". (Vs. 209-10).

Por último, complacido por los resultados de su concepción, y ya al término del "Arte nuevo....", Lope escribe:

"Sustento, en fin, lo que escribí y conozco que aunque fueran mejor, de otra manera no tuvieran (mis obras) el gusto que han tenido, porque a veces lo que es contra lo justo (lo clásico) por la misma razón deleita el gusto". (Vs. 362-367).

Ahora bien: la rebelión de Lope contra los preceptos clásicos debe ser entendida como un proceso de maduración. Menéndez Pidal ha escrito páginas insuperables al respecto. Seguir, siquiera a grandes rasgos, este sugestivo itinerario, es encararse con el problema dialéctico de la vena y el arte; esto es, con el conflicto que agobiaba a los tratadistas áureos y a sus predecesores. La pregunta meduiar inquiriạ lalpbesía, ¿nace espontáneamente en el alma de algunos hombres señalados, o es materia de aprendizaje, de artificio, de técnica?

Unos pensaban que la poesía era un don de Dios. No sin sorpresa leemos en Rengifo: "lo que parece cierto es que Ada (n) tuuo arte poetica infusa, y del la aprendieron sus hijos....", juicio éste que tiene un período de auge, muy anterior, en 'lla poesía trovadoresca: "la qual çiençia e orvisaçión e doctrina (la poesía) es avida por graçia infusa del señor Dios", nos dice Baena en su Cancionero. Y Fr. Luis de León, para marcar distintos tiempos de esta idea, escribe: "la poesía sin duda la inspiró Dios en los ánimos de los hombres, para con el movimiento y espíritu de ella levantarlos al cielo, de donde ella procede; porque poesía no es más que comunicación del aliento celestial y divino". Evidentemente, el demonio platónico, cristianizado, se cernía sobre la concepción de estos autores. 
Otros, por el contrario, negábanse - citaremos a Pinciano- "a mendigar al Cielo las causas de las cosas que puedo auer más acá abaro". Y, con espíritu "naturalista", explicaba así el nacimiento de la poesía: "El furor poético se pudiera reduzir más que los otros a la diuinidad, pero ni tal quiero confessar, porque si hallamos causas naturales y euidentes, ¿para qué auemos de yr a las sobrenaturales? Ingenio furioso es el del poeta, que es dezir un natural inuentiuo y machinador, causado de alguna destemplança caliente en el celebro. Tiene la cabeça del poeta mucho del elemento del fuego y así obra acciones inuentiuas y poéticas", añade el mismo López Pinciano, siguiendo ahora a Huarte de San Juan.

La idea de la poesía como impulso tenía, entonces, dos versiones:o derivaba de Dios mismo, o nacía de la naturaleza humana. Pero, además, algunos pensaban que la piedra de toque era el arte. A decir verdad, no era menudo el embrollo que tenían los tratadistas en sus cerebros. Sánchez de Lima, por ejemplo, comienza por decir que arle puede suplir a la vena, añade luego que el ideal sería conjugar inspiración y técnica, para terminar afirmando que, en definitiva, el "buen natural" es el que hace grandes a los poetas. En general, sin embaro, la postura triunfante correspondía a un eclecticismo más o menos armónico o más o menos confuso.

Ahora bien: ante este problema zqué actitud adopta Lope de Vega? En sus primeros años es evidente su devoción absoluta por la vena. "La poesía es inspiracion, vuelo alzado, furor natural. Y su desprecio por el arte es tajante, definitivo. En estos años escribe versos como:

"Que los que miran por guardar el arte nunca del natural alcanzan parte".

O también:

"Pero hacer versos y amar

naturalmente ha de ser".

Más explícita es su prosa

"Pues lo que la naturaleza acierta sin el arte es lo perfecto"

Como bien observa Menéndez Pidal, la actitud naturalista de Lope le viene, directamente, del romancero. Romancista inspirado, él sabía bien de las delicias de ceder al impulso creador y del alto vuelo del espíritu cuando suelta las amarras. Gozaba entonces al compás de la inspiración y deleitábase diciendo: 
"Estos romances, señora, nacen al sembrar el trigo"

Pero Lope, en su madurez, se da cuenta que, por no hilar fino, ha cometido un error. Y comienza por tener conciencia de que ha confundido arte con preceptos clásicos; esto es, una categoría general con una de sus manifestaciones históricas. Entonces, y sólo entonces, Lope se decide a escribir —obsérvese el título- el "Ãrte nuevo de hacer comedias". Ya no se opone, pues, al arte en general, sino a su versión clásica $y$, por tanto, deja de ser absoluto su culto hacia la naturaleza. Intenta armonizar el imperativo natural, la urgencia de vuelo, con el freno riguroso dei arte y sus cauces racionales, en una suerte de equilibrio inestable que se rompe con frecuencia a favor de su vieja fórmula naturalista. Empero, no volverá a olvidar que el impulso necesita un aparato racional que le otorgue peso, garantía y justificación.

El "Arte nuevo...", en última instancia, no es más que la plasmación de este esfuerzo por dotar de suelo racional a lo que había sido mera vena bullente y desbocada. Y así, Lope encuéntrase ante la necesidad de organizar un conjunto de nuevos preceptos, un nuevo arte. Se dirige entonces a "los que del arte no tratáis antiguo" y, seguramente incómodo, aconseja seguir los flamantes "aforismos" que expone en su obra. Pero Lope no era, reiteramos, un humanista isesúdo y sistemático Ea tarea le quedaba ancha y larga: el "Arte nuevo..." es a veces superficial, a veces inconexo, a veces vago e inseguro. Sin embargo, había cumplido con su destino. Rómpese en él el duro círculo que atenazaba la mente de los retóricos: ni arte - como normación clásica- ni vena -como impulso libérrimo-; sino un nuevo arte que retomara los mandatos de esa naturaleza, un nuevo arte que se sumergiera en la vida, en el hombre y su mundo histórico para extraer de allí los preceptos de la nueva retórica.

Por lo demás, Lope sabía que su obra no era definitiva. Tal vez sospechaba, eso sí, su destino de piedra de toque, de cimiento para la nueva arquitectura del teatro y el quehacer literario. Cuando sus íntimas voces le halagaban con murmullos de triunfo, Lope decía que su poética era la "poética invisible", la que no se ve porque se está gestando. Nosotros sabemos que su descendencia, como la de los justos, fue pronta, próspera y nutrida; y sabemos, además, que Lope -indeciso y genial-saltó la barrera de los versos dados y los versos fabricados que aún decía Valéry. 
Y la "poética invisible" fue dibujando su perfil. Tirso de Molinc y Alfonso Sánchez, creador el uno, catedrático el otro, se ocutaron de esta labor $y$, concientemente, se decidieron a construir el edificio que Lope había diseñado. Tal vez sea de interés señalar ahora, a manera de escorzo, los postulados centrales que Tirso y Sánchez formularon. Por lo pronto, y de inmediato, Alfonso Sánchez traió de hacer comprender que Lope jamás había roto su lanza contra toda normación artística. Era mejor olvidar la juventud del maestro y sus grandes protestas de entonces contra el arte en general. $Y$ es que Sánchez, perito en debates académicos, quería ganar la partida hurtando de antemano todo argumento a la parte contraria. De esta suerte, con habilidad escurridiza, insiste en demostrar, primero, que la doctrina de Lope no era un ccios: tenemos arte - decía- tenemos preceptos que nos obligan, y el precepto principal es imitir a la naturaleza, las costumbres y el ingenio del siglo en que se escribieron"; $y$, segundo, que Lope era más clásico que los pseudoclásicos renacentistas, pues él imitaba mejor a la naturelaza. La estrategia de Sánchez es manifiesta: ahora resulta que Aristóteles respalda a Lope y éste, sumiso, no hace más que bien interpretar al filósofo. La primera batalla de las universidades está ganada.

Pero la inquisición académica no cede fácilmente. Sánchiez es acosado y la polémica estalla. ¿Por qué - le preguntan- si Lope es fidelísimo seguidó de las concepciones glásicas, olvida más de uno de sus postulados concretos y crea obras, según propia confesión, al margen del arie? Francisco Sánehez medita y, al cabo, lanza su defensa - ahora menos estratégica pero más valiosa y profunda- apoyado en un concepto que hoy podríamos decir historicista: el arte progresa con el tiempo y sus principios se modifican con el iranscurrir de los siglos. Y nuevamente el defensor de Lope llama a Aristóteles: ¿acaso el Estagirita no decía que el arte imita la naturaleza y las costumbres y el ingenio del siglo? Entonces, ¿cómo no entender que el ingenio del siglo ha variado? No dilucidemos ahora si Sánchez, enfervorizado, distorciona o no el sentido de los textos aristotélicos, pero sí señalemos - subrayando- que se ha puesto en debate un principio de incalculables proyecciones: los_clásicos, dado que el arte progresa, no son modelos a seguir, sino estímulos por superar. Sánchez concluye dando rienda suelta a su retórica: ¿no es cierto - dice- que si Cicerón hablara ahora en la Universidad de Alcalá, sus oyentes sufrirían atroz aburrimiento? Los tiempos han variado y con ellos el 
gusto y el arte. La apología termina: "qué te importa magno Lope la comedia antigua, si tú has hecho mejores comedias para tu tiempo que Menandro y Aristófanes para el suyo?" Lope ha ganado la guerra de las universidades. Por algunos decenios, hasta que vengan Luzán y los Moratín, reynará tranquilo en el que fue reducto de sus enemigos.

Paralelamente y con argumentos similares, Tirso de Molina abre un nuevo frente: esta vez es el propio mundo del teatro. Las intenciones de Tirso son más concretas. Quiere demostrar a los hombres de teatro que las comedias de Lope son las mejores porque responden más fielmente al principio de la verosimilitud, como en el caso de su rebelión contra la unidad de tiempo. "Porque si aquellos establecieron que una comedia no representase sino la acción que moralmente se puede suceder en veinticuatro horas, ¿cuánto mayor inconveniente será que en tan breve tiempo un galán discreto se enamore de una dama cuerda, la solicite, regale y festeje, y que, comenzando a pretenderla por la mañana se case con ella por la noche? Estos inconvenientes - añade Tirso- mayores son en el juicio de cualquier.mediano entendimiento que el que se sigue de que los oyentes, sin levantarse de un lugar, vean y oigan cosas sucedidas en muchos días; pues así como el que lee una historia en breves planas, sin pasar muchas horas, se informe de casos sucedidos en largos tiempos y distintos lugares, la comedia, que es ună jumaen $y$ represeniaciónde un argumento, es fuerza que cuando le toma de los sucesos de dos amantes, retrata al vivo lo que les pudo acaecer y no siendo esto verosímil en un día, tiene la obligación de fingir que pasan los necesarios para que la tal acción sea perfecta". En un campo del teatro, Lope de Vega también había ganado su batalla. La "poética invisible" cada día adquiría nueva nitidez: su perfil estaba fijado para siempre.

Lope, como el Cid y al igual que todos los genios, lucha y triunfa hasta después de muerto. Aproximarnos al suelo racional que fecunda su teatro ha sido nuestra intención. $Y$ a punto de concluir ocúrresenos pensar que Lope viviente se ha escurrido de nuestras manos como arena fina o como luz. ¿Por qué entonces no tentar, en son de epílogo breve, una fijación de Lope en las coordenadas estéticas de su tiempo?

Lope es barroco. ¿Barroco este poeta impulsivo, diáfano, abierto, sencillísimo? Sí, barroco, pero no en la corteza, sino en la nuez. Y decía Berceo: "tolgamos la corteza e al meollo entremos". Vál- 
ganos pues el consejo del buen clérigo y advirtamos cómo así Lofe nos parece barroco.

Eugenio D'Ors suponía que el Barroco surgia como recicción ante lo slásico y lo renaciente, negando sus premisas estéticas. Dámaso Alonso y Pedro Salinas, más recientemente, opinan porque el barroquismo continúa la línea clásica y la lleva hasta sus últimas consecuencias. A nuestro criterio, asi lo han demostrado. Ahora bien: la tragedia de la literatura barroca en España, y también en Italia, Portugal e Inglaterra, fue la de carecer, casi en absoluto, de poder creador. De aqui su triste condición epigonal: al final de un largo proceso, agotados los manantiales del espíritu, descubre que tiene entre manos un cuerpo extenuado y agónico. Sin facultad creativa, no puede de nuevo iniciar el camino y se limita, entonces, a ocultar los rastros de muerte. He tenido oportunidad de decir que el attista barroco se me representa como una anciana -otrora bellísima - que cuida de su rostro poco antes de morir. Sus afeites y colores son el resultado del pavor: el pavor de que, de pronto, se traduzca la vividez del cadáver que será. Algunos deciden encarar su destino, jugar al juego del escondite, y naufragar con la nave: Góngora, por ejemplo. Otros, los menos, inician la fuga: Quevedo por el camino de la agudeza conceptual que, sin embargo, no crea, sino recrea $y$ distingue: afila. Lope, siempre contradictöfio, va y yiene, ensaya caminos, y a la postre, escapa del hundimiento. Pero su fuga lo ha marcado: es barroco en el fondo. "Jorge Puccinelli Converso"

Su actitud es típica y sintomática. A veces se inscribe en la tradición italianizante, como Góngora, y escribe a la manera de Garcilaso; a veces ostenta cultura y produce "La hermosura de Angélica"; a veces se aterra y dice esos romances que nacen al sembrar el trigo; a veces, por último, y gracias a Tomé Burguillo, rompe a reir -irreverente- de la tradición y nos habla de "Venus en pelota", como Velásquez del "Dios Marte". En esta inseguridad de trayectoria, nacida de la conciencia de que el Renacimiento está agotado y de que, sin embargo, atrae aún con sortilegio de ruinas; en este ir y venir de la tradición a la originalidad y de la sumisión a la rebeldía; en este vaivén entre el temor reverencial a lo clúsico y la ilusión de libertad, del culto a la irreverencia, se plasma el barroquismo de Lope. Y no importa mucho que su forma se mantenga en general sencilla, al margen de la fauna barroca siempre en estallido; lo que vale es su conciencia del apo- 
calipsis estético que entonces se vivía y sus conflictos internos, nacidos éstos de su circunstancia histórico-literaria.

Por esto, porque Lope es barroco, su estética es la de la naturaleza - selva y no la de la naturaleza- jardín, propia del Renacimiento.-Para Petrarca, como para Garcilaso, la belleza del mundo consistía en ser un paraje ameno, cuidado, cultivado y protegido; para Lope, en cambio, el mundo es un espectáculo de desenfreno vital y múltiple rostro: "que la abundancia, que algunos desestiman, a mí me persuade son el ejemplo de los campos; que el concierto breve de los jardines es inferior a la inmensa copia de la naturaleza, que en su variedad ha puesto hermosura", nos dice en frase esclarecedora.

Y recordemos, ahora, que Lope mezclaba lo trágico y lo cómico porque natura le decía que en la variedad moraba la belleza; que Francisco Sánchez y Tirso de Molina defendían a Lope porque su genio mimaba mejor la naluraleza; que -en fin-los romances nacían con el trigo, las comedias del naiural impulso y el nuevo arte de hacerlas, de oír alento los dictados de naturaleza. Entre tradición y originalidad, Lope de Vega dio su voto a farvor de la renovación, como lo dio también, y sobre todo, a favor del espíritu libre que sabe, de la raíz del tiempo, ascender a la eternidad.

\section{Biblioteca de Letras "Jorge Puccinelli Converso"}

